\title{
Mudanças do uso do território e reorganização da rede estadual de educação na cidade de São Paulo: estudo de caso na área da operação urbana Vila Sônia
}

\author{
Changes in the use of the territory and reorganization of the state \\ education network in the city of São Paulo: case study in the urban \\ operation area Vila Sônia
}

\author{
Eduardo Donizeti Girotto', Larissa de Campos"
}

\begin{abstract}
RESUMO
Neste artigo, analisamos as possíveis relações entre o projeto de reorganização da rede estadual de educação de São Paulo e as mudanças do uso do território na cidade de São Paulo. Para tanto, investigamos o processo de reorganização escolar na área que abrange a Operação Urbana Vila Sônia, na Zona Oeste da cidade de São Paulo. Para a construção da análise, realizamos levantamento documental nas diferentes secretarias e órgãos do governo estadual paulista e, a partir dos dados, produzimos uma série de mapas com o intuito de verificar possíveis correlações espaciais entre a reorganização escolar, a operação urbana e as mudanças no uso do território. A partir dos dados e dos mapas, realizamos uma série de trabalhos de campo que nos possibilitaram identificar intencionalidades semelhantes nas duas políticas analisadas, principalmente no que se refere à alteração dos usos do território em consonância com o processo de mercantilização do solo urbano na cidade de São Paulo.
\end{abstract}

Palavras-chave: Reorganização Escolar; Operação Urbana; Gestão Pública

\section{ABSTRACT}

In this article, we analyzed the possible relations between the reorganization project of the state education network of São Paulo and the changes in the use of the territory in the city of São Paulo. Therefore, we investigated the school reorganization process in the area that covers Operation Vila Sônia, in the West Zone of the city of São Paulo. In order to construct the analysis, we conducted a documentary survey of the different departments and agencies of the state government of São Paulo, and from the data, we produced a series of maps in order to verify possible spatial correlations between school reorganization, urban operation and changes in use of the territory. Based on the data and the maps, we carried out a series of fieldwork that allowed us to identify similar intentions in the two analyzed policies, especially regarding the alteration of land uses in line with the process of commercialization of urban land in the city of Sao Paulo.

Keywords: School Reorganization; Urban Operation; Public administration

'Doutor em Geografia Humana pela Universidade de São Paulo. Professor do Departamento de Geografia da Universidade de São Paulo. E-mail: egirotto@usp.br Orcid-ID: http://orcid.org/0000-0002-9870-6188

"Bacharelanda e Licencianda em Geografia na Universidade de São Paulo. E-mail: larissa2.campos@usp.br Orcid-ID: https://orcid.org/0000-0002-9275-0807 


\section{INTRODUÇÃO}

A reorganização escolar proposta pelo governo do Estado de São Paulo em 2015 previa o fechamento de 94 escolas e a transferência de mais 300 mil estudantes com o objetivo de implementar o ciclo único em 754 escolas do Estadoi. A justificativa baseava-se em análise realizada pela Coordenadoria de Informação, Monitoramento e Avaliação Educacional (CIMA) da Secretária Estadual de Educação, a partir do resultado do Índice de Desenvolvimento da Educação de São Paulo (IDESP) de 2014. Segundo o estudo, as escolas de ciclo único da rede estadual teriam desempenho 9,4\% acima da média, quando comparadas aquelas com mais de um ciclo.

O projeto foi duramente criticado por pesquisadores do campo educacional, tanto pela falta de clareza teórica e metodológicaii, quanto por não propor debate amplo e democrático com a comunidade escolar sobre o tema. Dada a pressão por parte da sociedade civil e a ocupação de mais de 200 escolas pelos estudantes, ainda em 2015 o governo estadual suspendeu o projeto.

Diversos aspectos permeiam a reorganização escolar: do ponto de vista educacional, poderíamos considerá-la como parte do processo da Reforma do Ensino Médioiii, com forte tendência à privatização do ensino através de desdobramentos via terceirização, apostilamento ou contratos de gestão privada para o ensino público. No entanto, ainda são escassas as fontes que associam esse processo a outros fatores, como a pressão internacionaliv e o avanço dos interesses do capital imobiliário na produção do espaço urbano. Em pesquisa recente, Franca (2010) articulou o processo de fechamento de unidades escolares na cidade de São Paulo, desde 1995, com o avanço de processos de valorização do espaço urbano. Em análise de caso, o autor demonstrou os múltiplos interesses presentes no fechamento das escolas, compreendendo a incorporação dos terrenos das unidades no processo de refuncionalização do espaço urbano na cidade de São Paulo. Em 2016, realizamos pesquisa na qual discutimos os 
possíveis impactos socioespaciais do projeto de reorganização escolar, demonstrando assim a importância de reconhecer a dimensão espacial das políticas públicas, bem como as diferentes formas de apropriação do espaço urbano por agentes que têm na reprodução da cidade uma de suas fontes de extração de lucro.

Dessa forma, o presente artigo tem o intuito de aprofundar as pesquisas iniciadas em 2016, buscando analisar as possíveis relações entre o projeto de reorganização das escolas estaduais e o processo de valorização do espaço urbano na cidade de São Paulo. Para tanto, investigamos o processo de reorganização escolar na área que abrange a Operação Urbana Vila Sônia, na Zona Oeste da cidade de São Paulo. Em concordância com Barros (2013), consideramos as operações urbanas parte da realização do capital financeiro e imobiliário na produção do espaço urbano, com implicações amplas nos usos do território. Em nossa hipótese, o fechamento de unidades escolares compõe um momento da alteração dos usos do território em consonância com o processo de mercantilização do solo urbano promovido pelas operações urbanas.

Para tanto, é fundamental ampliar o debate sobre o conceito de território para além de sua compreensão como base material para a ocorrência dos fenômenos sociais e naturais. Afirmar que a desigualdade é um dos elementos que contribuem para o entendimento da formação territorial brasileira é compreender o lugar que o território sempre ocupou no processo de reprodução ampliada do modo de produção capitalista. Como aponta Harvey,

A paisagem geográfica construída pelo capital não é um produto passivo. Evolui segundo determinadas regras práticas que - como as que governam a evolução combinatória das tecnologias - têm uma lógica autônoma, porém contraditória. O modo como a paisagem evolui afeta tanto a acumulação de capital quanto a maneira como se manifestam as contradições do capital e do capitalismo no espaço, no lugar e no tempo. A independência com que a paisagem geográfica evolui tem um papel fundamental na formação das crises. Sem o desenvolvimento geográfico desigual e suas contradições, há muito tempo o capital já teria se ossificado e se tornado caótico. Esse é um meio crucial pelo qual o capital se reinventa periodicamente. (2016, p. 139140) 
A capacidade de o capital se reinventar - sem, no entanto, resolver suas contradições fundamentais - implica a apropriação de novos territórios e a ressignificação dos antigos, conferindo-lhes novos usos. Em todos os casos as desigualdades se ampliam, uma vez que a apropriação nunca deixa de ser um processo de expropriação.

Nestes termos, é fundamental compreender o território não apenas na distribuição e localização geográficos dos objetos, mas também nas ações e usos que, socialmente, são produzidos. Concordamos com Silveira que:

a definição de qualquer pedaço do território deve levar em conta a interdependência e a inseparabilidade entre a materialidade e a ação, isto é, o trabalho e a política. Nesse quadro a vida da nação se desenvolve. É no território que as velhas técnicas permanecem e as novas se inserem para rearranjar o trabalho. Nele, as decisões políticas se gestam e nele se rebatem, dando valores diferentes às formas do trabalho e aos lugares. (SILVEIRA, 2011, p. 156)

Assim, no decorrer deste trabalho, buscaremos demonstrar como a Reorganização Escolar da Rede Estadual de São Paulo e a Operação Urbana Consorciada Vila Sônia reúnem um mesmo sentido de política pública que, ampliando a mercantilização do espaço, altera os usos do território, ampliando desigualdades, segregações e ferindo os direitos de diferentes sujeitos sociais.

No desenvolvimento da pesquisa observamos as seguintes etapas: o levantamento documental em sites e arquivos das secretarias municipais e estaduais de educação e planejamento. Entre tais documentos, destacam-se o Plano Diretor da Cidade de São Paulo, a Proposta da atual Reorganização Escolar, os dados referentes à dinâmica educacional e demográfica da cidade de São Paulo, o projeto de lei das Operações Urbanas Consorciadas, entre outros. Reunidos os documentos, analisamos os mesmos, estabelecendo o diálogo com os conceitos que compõem o arcabouço teórico-metodológico da pesquisa. Nesta etapa também foram produzidos mapas com a localização das escolas estaduais da zona oeste da cidade de São Paulo fechadas desde 1995 e daquelas que 
seriam fechadas na atual proposta de reorganização da rede estadual de educação. A partir desta análise comparativa preliminar, discutimos os resultados obtidos através do trabalho de campo e da produção dos mapas, apontando as possíveis correlações entre a proposta de reorganização escolar e a dinâmica da produção do espaço urbano presente na Operação Urbana Consorciada Vila Sônia.

Organizamos o artigo da seguinte forma: de início, apresentamos a Iocalização, caracterização e contextualização da área de estudo, seguida da análise das políticas de educação e da produção da cidade sob a égide neoliberal. Após isso, apresentamos as análises construídas a partir dos dados e documentos obtidos em campo, buscando discutir, nas considerações finais, as convergências entre a política educação e a produção do espaço urbano na área objeto de nossa investigação.

\section{DA OPERAÇÃO À REORGANIZAÇÃO: OS SENTIDOS DA POLÍTICA PÚBLICA SOB O NEOLIBERALISMO}

A Operação Urbana Consorciada Vila Sônia (OUCVS) faz parte do conjunto denominado de "Novas Operações", presente no Plano Diretor estratégico de São Paulo de 2002. Segundo o estatuto da cidade de 2001:

$\S 1^{\circ}$ Considera-se operação urbana consorciada o conjunto de intervenções e medidas coordenadas pelo Poder Público Municipal, com a participação dos proprietários, moradores, usuários permanentes e investidores privados, com o objetivo de alcançar em uma área transformações urbanísticas estruturais, melhorias sociais e valorização ambiental." (BRASIL, 2001, p.1)

O Mapa 1 demonstra o perímetro de todas as Operações Urbanas localizadas na Cidade de São Paulo, relacionando-as com a rede estrutural de transportes sobre trilhos, bem como com as escolas que seriam fechadas na proposta de reorganização escolar de 2015. 
Mapa 1. Operações Urbanas, Rede Estrutural de Transportes sobre trilhos e Escolas Fechadas


Fonte: Plano diretor estratégico, 2002

Fonte: Elabora pela autora, 2018.

Pelo mapa, é possível perceber a existência de correlação espacial entre o fechamento das escolas e o perímetro das operações urbanas. Esta correlação inicial nos levou a construir uma investigação mais pormenorizada da correlação entre os fenômenos e, para tanto, optamos por um estudo de caso no perímetro da Operação Urbana Vila Sônia, uma vez que, como aponta Franca (2010), tal área concentra um terço dos casos de fechamento de escolas em 1995, ano da primeira reorganização escolar da rede estadual.

A Operação Urbana Consorciada Vila Sônia (OUCVS) começou a ser elaborada em 2004, em função dos possíveis processos de valorização e transformação socioespacial que seriam gerados com a implantação da linha 
amarela do metrô e inauguração das estações Morumbi, Vila Sônia, Butantã e Pinheiros (ALVAREZ, 2015). Segundo a lei:

A primeira (e mais direta) razão pela qual o Plano Diretor Estratégico de 2002 de São Paulo elegeu a região Butantã-Vila Sônia - faixa territorial situada do oeste do rio Pinheiros - como lugar (tema e marco) de futura operação urbana remete à implantação da nova linha - 4, amarela- do metrô. Explorar de forma abrangente as possibilidades urbanísticas vinculadas à operação de sistemas de transporte público de massa constitui umas das principais diretrizes previstas e incentivada neste novo plano diretor. No caso da linha, o próprio traçado proposto soma um forte argumento extra em favor desta orientação (SÃO PAULO [CIDADE], 2014, p. 1)

O projeto da Operação Urbana Vila Sônia contava como intervenções públicas estruturais estratégicas como a conexão viária norte-sul e a criação de espaços públicos, com custo de aproximadamente R $\$ 210$ milhões. Apesar da Secretaria Municipal de Urbanismo e Licenciamento (SMUL) admitir que os estudos para a implantação da Operação Urbana Vila Sônia não tiveram continuidade desde o ano de 2011, o Plano Diretor Estratégico - PDE vigente, Lei n 16.050/14, alterou a previsão das futuras operações urbanas no município, definindo a criação delas somente no perímetro da Macroárea de Estruturação Metropolitana, não contemplando a Operação Urbana Consorciada Vila Sônia.

Com a implementação da OUCVS, a prefeitura de São Paulo esperava atrair 37 mil novos moradores para a região oeste até 2027 , além de arrecadar cerca de R\$300 milhões com a venda de Certificados de Potencial Adicional de Construção $(C E P A C)^{v}$, os quais seriam utilizados para viabilizar as intervenções futuras nesta área. Junto à Secretaria de Desenvolvimento Urbano, o município de São Paulo comprometeu-se com a valorização ambiental, a criação de habitação de interesse social e, principalmente, com a mobilidade ${ }^{\mathrm{v}}$. Todavia, o projeto foi duramente criticado por não contar com a participação dos moradores da região (BARROS, 2014).

Da mesma forma, a proposta de reorganização escolar foi duramente criticada por não contar com a participação dos diferentes sujeitos da educação em sua elaboração e tentativa de implementação. É importante ressaltar que se 
trata, em ambos os casos, de um modelo de política pública, alicerçado nos princípios da Nova Gestão Pública, umas das faces do neoliberalismo. Tal modelo assenta-se na defesa da gestão técnica da política, pautada no discurso do especialista competente e na pouca preocupação com a participação popular na elaboração, implementação e avaliação das políticas propostas.

A origem deste modelo, no caso das políticas educacionais no Brasil, pode ser encontrada ainda na década de 1960, com a assinatura dos acordos MEC/USAID e a consolidação da lei 5.692/71. Tais ações inserem no campo educacional uma série de conceitos e práticas vinculadas ao mundo empresarial. Na década de 1990, sob influência do Consenso de Washington, diversas reformas administrativas foram implementadas no Estado brasileiro. No campo das políticas educacionais, a efetiva participação das principais organizações internacionais - como o Banco Mundial, Fundo Monetário Internacional, etc. implicaram na reorientação dos gastos sociais, além da subordinação e dependência econômica dos países envolvidos às diretrizes desses órgãos.

Na última década do século XX, quase todos os países da América Latina iniciaram reformas educacionais resultantes, em grande medida, de um processo de indução externa liderado pelos organismos internacionais principalmente o Banco Mundial e o Banco Interamericano de Desenvolvimento -, que condicionaram a concessão de empréstimos aos Estados nacionais da região à implantação dessas reformas (KRAWCZYK, 2008, p. 15)

Diferentes países latino americanos têm adotado políticas de avaliação educacional conforme essa lógica neoliberal. Como resultado, verifica-se um mecanismo de controle com o intuito de incentivar e coibir certas práticas educativas de alunos e professores. Esse processo ocorre em decorrência da centralidade que as políticas de avaliação têm assumido no conjunto das políticas educacionais, sendo um dos pilares para o desenvolvimento dessas. A maioria das alterações ocorridas no campo educacional, seja no currículo, carreira docente, organização em ciclos de ensino etc., são justificadas a partir de resultados em avaliações centralizadas. 
Tal modelo estava presente no momento da apresentação da primeira proposta de reorganização escolar da Rede Estadual, em 1995, durante a gestão Mário Covas (PSDB) e que foi conduzida pela Secretária de Educação do Estado de São Paulo Rose Neubauer.

A então secretária Teresa Roserley Neubauer da Silva institui o "Programa de reorganização das escolas da rede pública estadual" que alterava a distribuição das classes, a partir de 1996, em escolas de Ciclo Básico à $4^{a}$ série; $5^{a}$ à $8^{a}$ série; $5^{\mathrm{a}}$ à $8^{\mathrm{a}}$ série e $2^{\circ}$ grau e $2^{\circ}$ grau5. [De acordo com a terminologia anterior à lei $n^{\circ}$ 9697/96]. (GOULART; PINTO \& BARBOSA, 2017, p. 2)

Entre o lançamento da proposta de reorganização escolar em 26 de outubro de 1995 e sua implementação com o decreto n. 40.473 em 21 de novembro passou-se menos de um mês. Apesar da velocidade, a mudança contou com uma ampla divulgação e a distribuição de 60 mil exemplares da cartilha "Mudar Para Melhorar". Nessa publicação, a Secretária Estadual de Educação enfatizava os pontos positivos da reorganização, colocando-a como fator essencial para a melhoria da qualidade de ensino e o aproveitamento dos alunos. Em relação às condições de trabalho docente, mencionava benefícios como turmas de 10 a 20 alunos e melhoria salarial dos professores. Todavia, o não envolvimento da sociedade civil organizada, bem como professores, pais e alunos, denuncia o conteúdo autoritário implícito da mudança implementada.

A reorganização da rede estadual foi uma estratégia para forçar a municipalização do ensino, como demonstra o decreto n. 41.054, de 29 de julho de 1996:

Fica a Secretaria da Educação autorizada a transferir unidades estaduais de ensino fundamental para as redes escolares municipais, pelo prazo de 5 (cinco) anos, em cumprimento dos objetivos do Programa de Ação de Parceria Educacional Estado-Município, instituído pelo decreto n. ${ }^{\circ} 40.673$, de 16 de fevereiro de 1996 (SÃO PAULO [ESTADO], 1996)

A redistribuição espacial dos alunos contribuiu para que a reforma atingisse seu principal objetivo: o enxugamento da rede oficial (FRANCA, 2010). Em todo o Estado de São Paulo a reorganização fechou 864 escolas e 2.031 escolas deixaram de oferecer curso noturno entre 1995 e 1999. 
Após 20 anos, a Secretaria Estadual de Educação de São Paulo anunciou uma nova reorganização escolar. Segundo o site institucionalvii, a proposta consistia na "disponibilização" (fechamento) de 94 escolas por todo estado (25 delas localizadas na cidade de São Paulo) e reestruturação de outras 754. Assim como a proposta de 1995, a redistribuição da rede teria como objetivo principal que cada unidade escolar atendesse um único ciclo da Educação Básica, focandose em uma mesma faixa etária. O argumento utilizado pela SEE-SP para o fechamento das escolas estava baseado em dois pontos principais: a mudança demográfica, pois, de acordo com a Secretaria, entre 1998 e 2015 a rede estadual perdeu cerca de 2 milhões de alunos, e o desempenho dos estudantes em avaliações externas.

Assim, é possível perceber que as duas reorganizações possuem similaridades, principalmente por serem processos que ocorreram em um contexto neoliberal de ampla transformação das políticas públicas educacionais. Observa-se um novo estágio do capitalismo monopolista, que exige mudanças essenciais na lógica de regulação nacional e institucional. Esse padrão tem buscado nortear não apenas a política educacional, mas se estende a outras políticas públicas, construindo, assim, uma tentativa de difundir a lógica empresarial e tecnicista como fundamento da ação do Estado no Neoliberalismo.

Assim, partimos do pressuposto que é necessário compreender as intencionalidades das propostas de Reorganização Escolar, tanto no âmbito educacional como no campo das políticas públicas, em especial, no que se refere a produção do espaço. É como base nesta hipótese que coletamos e analisamos os dados apresentados na próxima seção deste artigo.

\section{DA REORGANIZAÇÃO À PRODUÇÃO DO ESPAÇO URBANO: POSSÍVEIS CORRELAÇÕES}

O Mapa 2 apresenta as escolas fechadas no município de São Paulo em 1995 (de acordo com levantamento realizado por Franca, 2010) e as escolas que seriam fechadas na proposta da reorganização de 2015. 




Fonte: Dados da Secretaria Estadual de Educação de São Paulo. Elaborado pelos autores.

Observando o mapa é possível identificar uma mesma lógica espacial tanto na reorganização de 1995 como de 2015 (vide a proximidade dos dois conjuntos de unidades escolares mapeados). Na análise construída a partir das escolas fechadas em 1995, Franca (2010) identificou interesses não-educacionais no processo de reorganização escolar. Segundo o autor,

\begin{abstract}
Foram extintas 34 escolas entre 1995 e 2007, conforme levantamento realizado, entre o governo de Mário Covas e de José Serra, passando pelo governo de Geraldo Alckmin. Algumas delas foram reutilizadas para fins pedagógicos; outras foram reutilizadas em órgãos de outras secretarias do estado, como unidades da polícia militar; e algumas foram vendidas. É o caso da extinta EE Prof. José Alves de Camargo Vila Mafra, na Vila Formosa, onde foi construído um condomínio fechado, também foi o caso da EE Martim Francisco, na Vila Conceição, um caso emblemático da disputa pelos terrenos das escolas públicas nas áreas valorizadas pelo mercado imobiliário (FRANCA, 2010, P. 80-81)
\end{abstract}

A partir das conclusões do trabalho de Franca (2010), buscamos analisar as possíveis intencionalidades envolvidas no processo de reorganização escolar de 2015 articulando com lógica de mercantilização da cidade. Um dos primeiros 
aspectos que chama a atenção é que no documento que apresenta a proposta de reorganização de 2015, não são apresentados o destino dos terrenos das escolas que seriam fechadas. Por tratar-se de uma finalidade incerta, é possível inferir a relação entre o fechamento das unidades escolares e o ordenamento espacial proposto pelas OUC, avaliando a mudança de uso do território em favor da lógica dos agentes do capital, vinculados à dinâmica da especulação imobiliária.

No trabalho de campo foi possível identificar algumas intervenções complementares previstas no projeto, como a Requalificação da avenida Prof. Francisco Morato e da avenida Eliseu de Almeida, além da implantação da linha 4 - Amarela do Metrô no trecho Butantã - Vila Sôniaviii, compondo a paisagem e atraindo novos empreendimentos imobiliários para a região (Conforme Foto 1).

Foto 1: Obras da estação Vila Sônia do metrô (na Avenida Francisco Morato), ao fundo um novo empreendimento imobiliário em construção.



Fonte: Foto dos autores, maio de 2018.

Segundo Fioravanti (2014), é preciso ir além e considerar a OUCVS, assim como as demais Operações Urbanas previstas e vigentes em São Paulo ou demais projetos de requalificação urbana, como processos de valorização e de 
segregação que marcam a produção do espaço urbano. Nesse sentido, o valor gerado a partir de intervenções urbanísticas pode ser observado através dos lançamentos imobiliários, uma vez que, a mudança no padrão de moradia e nível social podem ser indicadores relevantes para considerar o avanço da especulação imobiliária em São Paulo nos últimos anos, como demonstra o Mapa

3, que apresenta os lançamentos imobiliários residenciais entre 1995-2013 (sistematizados pela EMBRAESP), com destaque para as escolas que seriam fechadas em 2015 no entorno.

Mapa 3. Lançamentos imobiliários residenciais entre 1995-2013 e escolas fechadas em 2015



Fonte: Elaborado pelos autores.

A partir da análise do Mapa 3 e da consequente associação entre os Lançamentos imobiliários residenciais e as escolas que seriam fechadas em 2015, é possível identificar uma correlação espacial entre as duas variáveis: há 
fechamento de unidade escolares em áreas com concentração de lançamentos imobiliários residenciais no período entre 1995 e 2013.

Com o intuito de verificar esta correlação, realizamos trabalhos de campo no entorno de 4 unidades escolares que seriam fechadas segundo a proposta da reorganização escolar. As imagens a seguir mostram alguns empreendimentos próximos a escolas que constam na lista no último projeto de reorganização e que estão contempladas pela faixa de domínio da Operação Urbana Consorciada Vila Sônia.

A primeira escola visitada foi a Keizo Ishihara que atende aos ciclos Fundamental I e II. O terreno da escola ocupa um quarteirão inteiro e destaca-se por sua localização estratégica entre a Avenida Corifeu de Azevedo Marques e a Rodovia Raposo Tavares, duas importantes vias da região Oeste de São Paulo. Outros equipamentos públicos como o Centro Educacional Esportivo do Butantã também estão presentes no entorno, além de uma base da Guarda Civil Municipal.

\section{Foto 2: Terreno da E.E. Keizo Ishihara}



Fonte: Foto dos autores, abril de 2018.

A paisagem do entorno da escola evidencia uma urbanização consolidada que segue a expansão do processo de verticalização presente no Distrito do Butantã. Atualmente, o preço médio por área útil dos lançamentos imobiliários no referido Distrito alcança $\mathrm{R} \$ \mathbf{7 . 0 2 4 , 1 5}$, de acordo com a EMBRAPA ${ }^{\text {ix }}$. Tal 
valorização acentua as desigualdades sociais na região, como é possível identificar na Foto 4, que retrata um senhor deitado no chão e, possivelmente, vivendo em situação de rua. Como ele, estima-se que 15.905 pessoas estejam na mesma condição na cidade de São Paulox.

\section{Fotos 3 e 4: Entorno da E.E. Keizo Ishihara}



Fonte: Fotos da autora, fevereiro de 2018.

O segundo ponto de parada foi na E.E Mary Moraes localizada na região conhecida como Super Quadra do Morumbi. A escola já atende em ciclo único (apenas Fundamental I), e, portanto, contradiz a justificativa da reorganização e, consequente, de fechamento apresentada pela SSE-SP.

Fotos 5 e 6: Fachada da E.E. Mary Moraes



Fonte: Fotos dos autores, junho de 2018. 
O entorno da escola conta com a presença da Unidade Básica de Saúde da Vila Praia. Na Foto 8 identifica-se parte da favela da Vila Praia contrapondo-se ao horizonte verticalizado pelos empreendimentos do Morumbi. Neste contexto, é possível inferir que o fechamento de escolas, se realizado, participaria de um processo contínuo de ressignificação da cidade, dando origem a "um novo espaço", para um outro público, capaz de assumir uma nova função (GIROTTO, 2016, GIROTTO et al, 2017).

Fotos 7 e 8: Comunicado colado no portão da Escola e Entorno da E.E. Mary Moraes.


Fonte: Fotos dos autores, junho de 2018.

O entorno da escola conta com a presença da Unidade Básica de Saúde da Vila Praia. Na Foto 8 identifica-se parte da favela da Vila Praia contrapondo-se ao horizonte verticalizado pelos empreendimentos do Morumbi. Neste contexto, é possível inferir que o fechamento de escolas, se realizado, participaria de um 
processo contínuo de ressignificação da cidade, dando origem a "um novo espaço", para um outro público, capaz de assumir uma nova função (GIROTTO, 2016, GIROTTO et al, 2017).

As últimas escolas visitadas estão localizadas no Distrito da Vila Sônia onde a revalorização do espaço urbano está diretamente vinculada às obras de transporte e de mobilidade urbana, reforçando a correlação entre a valorização do solo e o fechamento das escolas. A Foto 9 retrata o Condomínio Bairro Paulistano e ao fundo o Condomínio Quintas do Morumbi, ambos localizados no entorno das duas unidades escolares que seriam fechadas na reorganização de 2015 na Vila Sônia. Reforçando a ideia de valorização da região, evidenciamos a proximidade dos empreendimentos imobiliários de alto padrão ao Portal do Morumbi e ao $89^{\circ}$ Departamento de Polícia Portal do Morumbi.

\section{Foto 9: Condomínio Bairro Paulistano}



Fonte: Foto dos autores, agosto de 2018. 
A E.E. Adalgiza Segurado da Silveira, assim como a E.E. Mary Moraes, atua em ciclo único e atende ao Fundamental I. O terreno da escola ocupa uma posição privilegiada em um dos pontos mais altos do bairro Jardim Monte Kemel. Além disso, possui acesso direto à Avenida Professor Francisco Morato, uma das principais da Região.

Foto 10: E.E. Adalgiza Segurado da Silveira



Fonte: Foto dos autores, junho de 2017.

Fotos 11 e 12: Entorno da E.E. Adalgiza Segurado da Silveira



Fonte: Fotos dos autores, respectivamente em novembro de 2017 e junho de 2018.

Os trabalhos de campo realizados no entorno da escola demonstram que o uso do território é feito pelos moradores das áreas mais periféricas ao bairro, uma vez que são esses mesmos sujeitos que frequentam a escola junto a outros alunos vindos de lugares próximos como Favela de Paraisópolis, retratada no 
fundo da Foto 12. Dessa forma, é possível inferir que a mudança do uso do território no distrito da Vila Sônia revela um intenso processo de segregação socioespacial promovido pela reorganização escolar e vinculado ao cerceamento do direito e acesso à escola e ao território.

Presente no mesmo contexto de formação socioespacial, a última escola visitada foi a E.E. Pedro Fonseca, que atende aos ciclos Fundamental II e Médio. Como já mencionado, seu entorno revela a mudança do uso do território, uma vez que a escola está localizada numa área de concentração de lançamentos imobiliários de alto padrão voltados para atração de novos moradores que dificilmente representarão demanda para o ensino público.

\section{Foto 13: Fachada da E.E. Pedro Fonseca}



Fonte: Foto dos autores, junho de 2018.

A Foto 14 evidencia o processo de verticalização no horizonte da escola e a mudança no padrão de moradia do bairro. Devido à proximidade com a Avenida Professor Francisco Morato, principal eixo de ligação entre o Bairro e a região Central da cidade de São Paulo, podemos caracterizar o uso desse território a partir da valorização do solo urbano impulsionada pelas obras de infraestrutura 
como o Corredor de Ônibus e a futura estação Vila Sônia da Linha 4 - Amarela do Metrô.

Foto 14: Horizonte da E.E. Pedro Fonseca na perspectiva de dentro da escola.



Fonte: Foto dos autores, junho de 2017.

Portanto, retornando a hipótese inicial da pesquisa, que buscava inferir variáveis não só educacionais ao processo de fechamento das unidades escolares, associamos o Mapa 1 das Operações Urbanas, a Rede Estrutural de Transportes sobre trilhos e Escolas Fechadas em 2015 com o Mapa 3 e observamos a reestruturação da cidade a partir de eixos e obras de transporte e mobilidade urbana, sendo possível estabelecer a correlação espacial desses fatores. Com o trabalho de campo, foi possível verificar que há um processo de mudança do espaço urbano, vinculado tanto à Operação Urbana quanto ao processo de reorganização escolar que pode implicar em alterações significativas do uso do território, com possíveis impactos na ampliação das desigualdades socioespaciais.

Assim, é possível verificar que ambas as políticas reforçam a lógica de mercantilização da cidade, o que fica mais evidente quando analisamos quem são 
os sujeitos das mesmas. No caso da zona oeste de São Paulo, temos uma parceria público privada constituída no Consórcio Via Quatro da Linha Amarela do Metrô, pressupondo um ordenamento territorial estabelecido por três grupos o Mitsuri (10\%), RuasInvest (15\%) e o majoritário CCR (75\%). ${ }^{\text {i }}$

É interessante ressaltar que o Grupo CCR responde pela concessão de rodovias, mobilidade urbana, aeroportos e serviços, sendo 55,23\% de suas ações ordinárias negociadas no Ibovespa Novo Mercado, modelo composto 89\% por

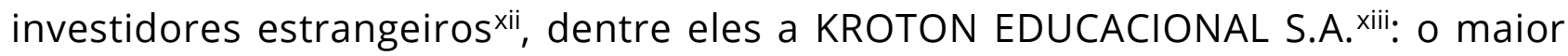
grupo educacional do mundo que já atua na educação básica por intermédio de editoras como a Scipione e a Saraiva, especializadas em livros didáticos oferecidos para 33 milhões de estudantes de escolas públicas ${ }^{\text {xive }}$ influenciando diretamente os conteúdos que serão acessados nas escolas.

Tais relações econômicas norteiam o ordenamento territorial revelando uma mesma intencionalidade das políticas públicas, tanto no fechamento das escolas como na reprodução da cidade. Nesse sentido, reproduz-se uma lógica de política pública que, definindo os usos do território e os sujeitos deste uso, amplia as desigualdades socioespaciais, reforçando aquilo que Santos (1988) denominava de espaço sem cidadão. Por isso, a disputa pela política pública, seus sentidos e ações, é também uma disputa pelo território e seus usos, sendo que a mesma contempla ações estruturais de equidade, como indicam as conclusões desse estudo.

\section{CONSIDERAÇÕES FINAIS}

A hipótese inicial desse trabalho buscava compreender se a política pública da reorganização escolar estava vinculada a interesses econômicos e não apenas educacionais. A partir da pesquisa foi possível constatar a correlação espacial entre os dois fenômenos e, como partes de uma mesma lógica de gestão do Estado no capitalismo, tanto a reorganização da rede estadual como a Operação 
Urbana Vila Sônia visam mudar os usos do território. Ambas negam o uso do território para os sujeitos sociais que, porventura, não atribua valor de troca ao mesmo e, portanto, têm seu direito de uso cerceado - reforçando desigualdade de classe, étnico-raciais, de gênero, etc.

No entanto, apesar desta lógica hegemônica de gestão do Estado Neoliberal buscar se consolidar a partir das duas políticas públicas analisadas, é possível perceber que, no território, se constroem usos não hegemônicos, que ressignificam a política e os seus sentidos. Tais resistências no e do território podem ser amplamente destacadas no processo de ocupação das escolas realizadas pelos estudantes secundaristas de todos o Estado, demonstrando a força do lugar e do território em uso por aqueles que nele habitam. A importância das ocupações, de todas as ordens e tipos, apresentou-se como fôlego necessário para a continuidade dessa e de outras pesquisas com o compromisso de pensar políticas públicas equitativas.

Por isso, em nossa perspectiva, é fundamental que avancemos na construção de alternativas à gestão pública vinculada às demandas do capital. Parte destas alternativas vêm sendo construídas a partir da consolidação de instâncias deliberativas e de controle social expressas nos Conselhos de Escolas, Movimentos Estudantes, Grêmios Escolares, Conselhos Municipais de Habitação, além de fóruns sociais e populares (de moradia, educação, saúde, etc.). Além disso, é importante destacar também a consolidação de espaços de cultura e socialização de ideias e saberes em diferentes territórios da cidade de São Paulo, como os "slam resistência", os cursinhos comunitários, os saraus e as mais diferentes organizações comunitárias. Tratam-se de movimentos e sujeitos essenciais ao desafio da materialização democrática de políticas de descentralização que garantam acesso e qualidade ao serviço público, levando em conta as ainda gritantes desigualdades regionais e preservando o princípio da transparência de processos e ações. 
Todas estas experiências vão na direção da consolidação dos direitos territoriais, fundamentais ao enfrentamento do desafio da equidade. Como aponta Santos (1988),

Há desigualdades sociais que são, em primeiro lugar, desigualdades territoriais, porque derivam do lugar onde cada qual se encontra. Seu tratamento não pode ser alheio às realidades territoriais. O cidadão é um indivíduo num lugar. A República somente será realmente democrática quando considerar todos os cidadãos como iguais, independentemente do lugar onde estejam (p. 123).

Que as denúncias e anúncios deste texto possam contribuir na construção desta República efetivamente democrática, um pleno espaço de cidadãos.

\section{REFERÊNCIAS}

ALVAREZ, IP. A produção e reprodução da cidade como negócio e segregação. In: CARLOS, A. F. A; VOLOCHKO, D; ALVAREZ, IP (orgs.) A cidade como negócio. São Paulo: Editora Contexto, 2015.

BARROS, Marli de. Operação Urbana Consorciada Vila Sônia: conflitos socioespaciais na reprodução da metrópole. 2013. Dissertação (Mestrado em Geografia Humana) - Faculdade de Filosofia, Letras e Ciências Humanas, Universidade de São Paulo, São Paulo, 2014. doi:10.11606/D.8.2014.tde-07042014- 115026. Acesso em: 2017-05-06.

FIORAVANTI, LM. A operação urbana Butantã - Vila Sônia e a (re) produção do espaço urbano em São Paulo: estratégias e conflitos. Confins [Online], 22 | 2014, posto online no dia 25 Novembro 2014, consultado o 13 Fevereiro 2018. URL : http://journals.openedition.org/confins/9767; DOI : 10.4000/confins.9767

FOUCAULT, Michel. O nascimento da medicina social. In: FOUCAULT, Michel. Microfísica do poder. 22 ed. Tradução Roberto Machado. Rio de Janeiro: Graal, 1979.

FRANÇA, G. C. Urbanização e Educação: da escola de bairro à escola de passagem. Tese de Doutorado. São Paulo: FFLCH-USP, 2010.

GIROTTO, Eduardo Donizeti et al. A geografia da reorganização escolar: uma análise espacial a partir da cidade de São Paulo. ETD - Educação Temática Digital, Campinas, SP, v. 19, p. 134158, mar. 2017. ISSN 1676-2592. Disponível em: http://periodicos.sbu.unicamp.br/ojs/index.php/etd/article/view/8647805. Acesso em: 19 mar. 2017.

GOULART, Débora Cristina; PINTO, José Marcelino Rezende; CAMARGO, Rubens Barbosa de. Duas reorganizações (1995 e 2015): do esvaziamento da rede estadual paulista à ocupação 
das escolas. ETD - Educação Temática Digital, Campinas, SP, v. 19, p. 109-133, mar. 2017. ISSN 1676-2592. Disponível em: https://periodicos.sbu.unicamp.br/ojs/index.php/etd/article/view/8647797/15186.\%20Acesso \%20em:\%203\%20fev.\%202018.\%20doi:http:/dx.doi.org/10.20396/etd.v19i0.8647797 Harvey, D. (2014). Cidades rebeldes. São Paulo: Martins Fontes, 2014. Harvey, D. (2016). 17 contradições e o fim do capitalismo. São Paulo: Boitempo, 2016

KRAWCZYK, NR. A reforma educacional na América Latina: uma perspectiva históricosociológica. São Paulo: Xamã, 2008.

MOREIRA, Ruy. O espaço e o contra-espaço: as dimensões territoriais da sociedade civil e do Estado, do privado e do público na ordem espacial burguesa. In: Santos, Milton et al. Território, territórios: Ensaios sobre o ordenamento territorial. 2. ed. Rio de Janeiro: DP\&A, 2006

OLIVEIRA, DA. (org.). Gestão democrática da educação; desafios contemporâneos. Petrópolis: Vozes, 1997

REDE ESCOLA PÚBLICA UNIVERSIDADE. Análise da resposta da Secretaria da Educação do Estado de São Paulo (Departamento de Planejamento e Gestão da Rede Escolar e Matrícula DGREM) à Ação Civil Pública (ACP) movida pelo Ministério Público do Estado de São Paulo e Defensoria Pública do Estado de São Paulo, processo n. 1049683-05.2015.8.26.0053. São Paulo, 2016. Disponível em:

http://www.observatoriodaeducacao.org.br/images/pdfs/nota.tecnica.\%20reorganiza cao.2016.pdf. Acesso em: 7 nov. 2016.

SANTOS, M. Sociedade e Espaço: A Formação Social como Teoria e como Método. Boletim Paulista de Geografia, São Paulo, n.54, p.81-100, jun. 1977.

SANTOS, M. Pensando o espaço do homem. São Paulo: Hucitec, 1982.

SANTOS, M. O espaço do cidadão. Nobel: São Paulo, 1988.

SANTOS, M. A Natureza do espaço: técnica, razão e emoção. 4. ed. São Paulo: Editora da Universidade de São Paulo, 2004.

SANTOS, M. Técnica, espaço, tempo: globalização e meio técnico-científico- informacional. São Paulo: Editora da Universidade de São Paulo. 2008

SANTOS, M; SILVEIRA, M. L. O Brasil: território e sociedade no início do século XXI.

São Paulo: Record, 2001

SANTOS, M; SILVEIRA, M. L. O Brasil: território e sociedade no início do século 21. A história de um livro. Acta Geográfica, ed. esp., 151-163, 2011. 
BRASIL. Lei Federal $n^{\circ} 10.257$ de 10 de julho de 2001. Regulamenta os arts. 182 e 183 da Constituição Federal, estabelece diretrizes gerais da política urbana e dá outras providências. (Estatuto da Cidade) São Paulo, 10 de julho de 2001.

SÃO PAULO (Estado). Mudar para melhor: uma escola para criança e outra para o adolescente - reorganização das escolas da rede estadual. São Paulo: SEE, 1995.

SÃO PAULO (Estado). Resolução SE 2. São Paulo: SEE, 2016

SÃO PAULO (Estado). Decreto n. 40.473, de 21 de novembro de 1995. Institui o Programa de Reorganização das Escolas da Rede Pública Estadual e dá providências correlatas. Palácio das Bandeiras, 21 de novembro de 1995.

SÃO PAULO (Estado). Decreto n. 41.054, de 29 de julho de 1996. Autoriza a Secretaria da Educação a adotar providências relativas ao Programa de Ação de Parceria Educacional Estado-Município e dá providência correlata. Diário Oficial - Executivo, 30/07/1996, p.1

SÃO PAULO (Estado). Lei $\mathrm{n}^{\circ}$ 13.430, de 13 de setembro de 2002. Institui o Plano diretor estratégico. Diário Oficial do Município, São Paulo, 13 maio, 2004a. Suplemento especial.

SÃO PAULO (Cidade). Lei $\mathrm{n}^{016.050 / 14}$, de 31 de julho de 2014. Institui o Plano diretor estratégico. Diário Oficial do Município, São Paulo, 31 de Julho de 2014.

\footnotetext{
' Dados oficiais da Secretaria da Educação do Estado de São Paulo, 2015. Disponível em: http://www.educacao.sp.gov.br/reorganizacao.Acesso em: 05 de ago 2017.

ii Analise de professores da Universidade Federal do $A B C$ (UFABC) contesta reorganização escolar em São Paulo. Disponível em: http://educacao.estadao.com.br/noticias/geral,analise-de- universidadefederal-contesta-reorganizacao-escolar-em-sp,10000003458. Acesso em: 05 de ago 2017.

iii Senado aprova MP do ensino médio e encaminha texto para sanção presidencial. Acesso em: http://www2.planalto.gov.br/acompanhe-planalto/noticias/2017/02/senado-aprova-mp-do-ensinomedio-e-encaminha-texto-para-sancao-presidencial. Acesso em: 05 de ago 2017.
}

iv Documento elaborado pelo Banco Mundial em 2012 aponta concepções sobre a Educação Brasileira. Segundo este um dos problemas principais da Educação Brasileira é o "alto custo do professor no país". Disponível em:

http://portal.mec.gov.br/index.php?option=com_docman\&view=download\&alias=7289-banco-mundialpdf\&Itemid=30192. Acesso em: 09 Set 2017.

v Como a lei desta Operação Urbana não foi aprovada, não houve emissão ou venda de nenhum título CEPAC, segundo a Secretaria Municipal de Urbanismo e Licenciamento (SMUL).

vi Operação Urbana Vila Sônia. Prefeitura do Município de São Paulo Secretaria Municipal de Desenvolvimento Urbano - SMDU Assessoria Técnica de Operação Urbana - ATOU, 2011. Disponível em:

http://www.prefeitura.sp.gov.br/cidade/secretarias/upload/desenvolvimento_urbano/arquivos/OUVS_a gosto2011.pdf. Acesso: 10 fev 2018.

vii Reorganização Escolar é adiada para garantir o diálogo com comunidade escolar em 2016. Disponível em: http://www.educacao.sp.gov.br/reorganizacao/. Acesso em: 01 dez 2015. 
viii Apresentação do projeto urbanístico da Operação Urbana Vila Sônia à comunidade. Disponível em: http://www.prefeitura.sp.gov.br/cidade/secretarias/upload/desenvolvimento_urbano/arquivos/OUVS_a gosto2011.pdf Acesso: 21 de mai 2018

ix O preço médio por metro quadrado de área útil destes lançamentos mostra que o Butantã é mais caro que o Morumbi: $R \$ 7.024,15$ contra $R \$ 6.780,71$ - uma diferença de $R \$ 243,44$, de acordo com a EMBRAPA. Disponível em: https://economia.estadao.com.br/blogs/radar-imobiliario/morumbiapresenta-metro-quadrado-mais-barato-que-butanta/ Acesso: 05 ago 2018.

x Número de pessoas em situação de rua na cidade de São Paulo, 2000 a 2015. Disponível em: https://www.prefeitura.sp.gov.br/cidade/secretarias/upload/assistencia_social/observatorio_social/201 5/censo/FIPE_smads_CENSO_2015_coletivafinal.pdf Acesso: 05 ago 2018.

xi Estrutura acionária da Via Quatro. Disponível em: h: http://www.viaquatro.com.br/a-viaquatro/estrutura-acionaria. Acesso em 30 jul 2018.

xii Estrutura de acionistas controladores alinhados e comprometidos com as melhores práticas de Governança Corporativa da CCR. Disponível em: http://www.grupoccr.com.br/grupo-ccr/estruturaacionaria . Acesso em 30 jul 2018.

xiii Listas de empresas Ibovespa Novo Mercado http://www.bmfbovespa.com.br/pt_br/produtos/listados-a-vista-e-derivativos/rendavariavel/empresas- listadas.htm Acesso em 30 jul 2018.

xiv Educação no mercado: Kroton vai às compras. Disponível em: http://www.cartaeducacao.com.br/artigo/educacao-no-mercado-kroton-vai-as-compras/. Acesso em 30 jul 2018. 